\title{
El aborto en México: el debate en la Suprema Corte sobre la normativa del Distrito Federal
}

Este comentario, junto a los documentos que analiza, está disponible en www.anuariocdh.uchile.cl

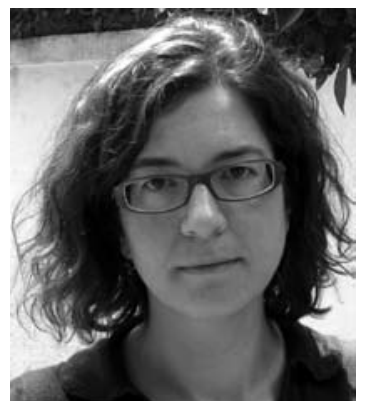

\section{Francisca Pou Jiménez}

Licenciada en derecho por la Universidad Pompeu Fabra de Barcelona -donde obtuvo también una especialización en derecho público- y maestra y doctora en derecho por la Universidad de Yale. Ha sido profesora de derecho constitucional y de derecho comunitario europeo y actualmente trabaja como letrada en la Suprema Corte de Justicia de la Nación de México.

pougimenez@yahoo.es

\section{RESUMEN}

El artículo da cuenta de la discusión desarrollada el pasado año en la Suprema Corte mexicana a raíz de la impugnación de la ley del Distrito Federal que legalizó la interrupción voluntaria del embarazo durante el primer trimestre. Para favorecer la comprensión de la sentencia y contextualizar la litis, el artículo describe los principales rasgos de la regulación del aborto en la Federación mexicana, así como una primera resolución de la Corte sobre el tema del año 2002. A continuación describe las impugnaciones que derivaron en la sentencia del 2008 y expone los argumentos que apoyan la declaración de validez de las normas impugnadas. El artículo destaca, finalmente, algunos rasgos notorios del tipo de estrategia argumentativa adoptada por la Corte, como la ambigüedad del análisis sobre el estatuto constitucional del concebido, la escasez de pronunciamientos en materia de derechos y la opción por construir el razonamiento que justifica la constitucionalidad de la ley apelando fundamentalmente al margen de maniobra que la Constitución mexicana otorga al legislador para penalizar o despenalizar conductas.

La reforma al Código Penal del Distrito Federal (CPDF) que legalizó la interrupción del embarazo durante las primeras doce semanas y su posterior impugnación ante la Suprema Corte mexicana, suscitó un debate social y político muy amplio en México y levantó un apreciable interés en toda América Latina. Era la primera vez en la región que una corte constitucional analizaba un esquema más permisivo que el de la habitual despenalización por "indicaciones", y la Corte mexicana recibió escritos y amicus curiae elaborados por organizaciones no gubernamentales de todo el continente ${ }^{1}$.

1 La falta de regulación formal del amicus curiae en la normativa procesal no inhibió en este caso la aceptación por la Corte de literalmente cientos de escritos, cartas y correos electrónicos (aunque dificulta su clasificación y diluye, en mi opinión, la visibilidad y el peso relativo de los documentos verdaderamente orientados a proveer datos y argumentos relevantes). La intensa movilización ciudadana en torno al caso llevó también a la Corte a celebrar seis audiencias públicas en las que particulares y agrupaciones pudieron exponer sus puntos de vista. A la ingente cantidad de información y opinión 
En el momento de cerrar este artículo (y debido al sistema de elaboración de resoluciones de la Corte, al que me referiré más adelante) contamos solamente con el texto que recoge la opinión común de los ocho Ministros que integraron la mayoría, y no con los votos concurrentes y particulares que, sin duda, serán importantes para perfilar con mayor precisión el alcance de una sentencia a cuya conclusión básica - declarar la constitucionalidad de la normativa del Distrito Federal (DF)- Ilegaron los Ministros por motivos notablemente distintos ${ }^{2}$. El objetivo del trabajo será proveer de una primera descripción de los argumentos con los que se justificó la constitucionalidad de la reforma que ayude a identificar las peculiaridades de la controversia mexicana sobre el aborto y sitúe la sentencia del 2008 en un ámbito de debate y análisis regional.

En cualquier caso, parece aconsejable acompañar al análisis de los argumentos una descripción de la litis a la que pretendían dar respuesta (en el contexto de un texto constitucional con singularidades no siempre conocidas) y, más en general, proveer datos que esbocen de algún modo los antecedentes y el contexto regulativo de la decisión. Por ello empezaremos con un apartado que describe cómo está regulada la interrupción del embarazo en la Federación mexicana y que da cuenta brevemente de la evolución de la legislación del DF en la materia. Esta legislación ya fue impugnada ante la Corte mexicana en una ocasión anterior y dio origen a una sentencia del año 2002, cuyas principales conclusiones también recordaremos. Con posterioridad, describiremos las alegaciones de las acciones interpuestas contra la reforma del 2007 y sintetizaremos las principales líneas argumentativas manejadas por la sentencia del 2008.

Concluiremos con unos comentarios breves orientados a subrayar algunas de las particularidades más notorias de la resolución mexicana y a sugerir algunos de los escenarios que puede propiciar, a la vista de la legislación vigente en otras entidades federativas y dada la evidente relación entre la interrupción del embarazo y otros temas que los tribunales mexicanos pueden verse pronto en la necesidad de abordar.

\section{Contexto legislativo general}

La regulación de la interrupción del embarazo en México es un mosaico de regímenes jurídicos que distan de ser idénticos. Las sedes tradicionales de esta regulación han sido los códigos penales y las leyes de salud de los 31 Estados federados y del DF, los cuales son en principio los titulares de las competencias normativas y ejecutivas más relevantes en la materia ${ }^{3}$.

La mayoría de estas regulaciones tienen rasgos comunes y fueron emitidas en los años treinta del siglo pasado. El esquema general es el modelo clásico que define el aborto como un delito al que se anuda una pena de prisión muy variable (4 meses en el extremo inferior y 12 el superior), a la que se adiciona por regla general una sanción pecuniaria y la suspensión de ejercicio profesional para el personal sanitario involucrado. Prácticamente en todos los casos la pena se distribuye en niveles de gravedad según la identidad del sujeto que practica el aborto, según cuente o no con el consentimiento de la embarazada y según la naturaleza de los medios empleados (violentos o

producida por estas vías deben añadirse los informes solicitados por el Ministro instructor a organismos públicos del sector salud y del sistema de administración de justicia, y varios dictámenes periciales.

2 Para la reconstrucción de sus posturas contamos, además, con las constancias de la discusión plenaria del asunto. Desde hace unos años y como parte de una política institucional muy abierta en materia de transparencia y acceso a la información, las discusiones del Pleno son públicas y se difunden por internet y por un canal de televisión específico (el Canal Judicial).

3 Las posiciones constitucionales del DF y de los Estados no son idénticas, pero las diferencias no son relevantes para el presente análisis, que los considerará en un mismo grupo y en contraste con la Federación. Aunque la salud es claramente una de las materias de competencia relevantes cuando del aborto se trata, sólo ocho de las leyes estatales de salud contienen regulación al respecto. 
no violentos). Por sorprendente que resulte, nueve de los códigos continúan previendo atenuantes para los abortos relacionados con "ocultación de la deshonra" 4 .

La tipificación de la conducta viene acompañada de un listado variable de causas de justificación o de exclusión de pena. La única hipótesis que hallamos en todos los Estados es la interrupción de embarazos producto de una violación, caso al que se asimila en 11 Estados la interrupción de los derivados de una inseminación artificial no consentida 5 . El aborto imprudencial se castiga en dos Estados (Chiapas y Nuevo León). El aborto practicado cuando el embarazo pone en riesgo la vida de la mujer está despenalizado en 23 Estados de manera expresa y en tres más de manera indirecta, en tanto puede considerarse cubierto por la despenalización de los casos en que existe grave riesgo para su salud ${ }^{6}$. Sin embargo, son sólo 11 -un tercio del total- los Estados cuyos códigos excluyen la antijuridicidad o la imposición de la pena cuando el embarazo pone en riesgo la salud de la madre. La indicación eugenésica (casos en que el embrión o feto tiene malformaciones graves) está prevista en 13 de los 32 códigos examinados. La única regulación (dejando ahora de lado las novedades introducidas en el DF por la última reforma) con previsiones que no pueden reconducirse a las tres indicaciones clásicas (terapéutica, eugenésica y ética) es la de Yucatán, que descarta la imposición de la pena cuando el aborto "obedezca a causas económicas graves y justificadas" y la persona tenga ya tres hijos ${ }^{7}$.

El Código Penal Federal también cuenta con previsiones en materia de aborto ${ }^{8}$. Conforme con los artículos 329 a 334, se trata de un delito cuya comisión amerita la imposición de una pena de entre 6 y 8 años de prisión, según las circunstancias y la calidad de los sujetos involucrados. Sólo el aborto causado por imprudencia, el que interrumpe un embarazo producto de una violación y el que resulta necesario para enfrentar una situación en la que la mujer corre peligro de muerte, resulta no punible.

Ha sido en el DF - una entidad con tendencias políticas menos conservadoras que las prevalecientes en el resto del país- donde se han dado las principales innovaciones legislativas en la materia. En el año 2000, sobre la base de una iniciativa del Gobierno de la ciudad, la Asamblea

4 En Durango y en el Estado de México se prevé una pena menor cuando la mujer da muerte al producto "para ocultar su deshonra" (artículos 352 y 250, respectivamente). El resto de los códigos aludidos usan una fórmula (presente también en el Código federal) según la cual se aminora la pena cuando la mujer: i) no tiene mala fama; ii) ha logrado ocultar su embarazo; iii) éste deriva de una unión ilegítima; iv) el aborto se efectúa durante los primeros cinco meses de embarazo (Jalisco: 228; Nayarit: 336; Oaxaca: 315; Puebla: 342; Tamaulipas: 359; Yucatán: 392; Zacatecas: 311 ).

5 Los artículos relevantes de los códigos penales referidos son los siguientes: Aguascalientes: 7-9 y 93; Baja California: 132-136; Baja California Sur: 249-252; Campeche: 294-299; Coahuila: 357-361; Colima: 187-191; Chiapas: 178-183; Chihuahua: 143-146; Durango: 350-352; Guanajuato: 158-163; Guerrero: 116-121; Hidalgo: 154-158 (reformado apenas el 21-4-2008); Jalisco: 227-229; Estado de México: 248-251; Michoacán: 285-291; Morelos: 115-119; Nayarit: 335-339; Nuevo León: 327-331; Oaxaca: 312-316; Puebla: 339-343; Querétaro: 136-142; Quintana Roo: 92-97; San Luis Potosí: 128-130; Sinaloa: 154-158 Sonora: 265-270 Tabasco: 130-136; Tamaulipas: 356-361; Tlaxcala: 277-280; Veracruz: 149-154; Yucatán: 389-393; Zacatecas: 310-313; Distrito Federal: 144-148. Todos ellos están disponibles en www.ordenjuridico.gob.mx [consultada el 12 de diciembre de 2008].

6 Los Estados que no despenalizan el aborto aunque la continuación del embarazo ponga en peligro la vida de la mujer son Guanajuato, Guerrero y Querétaro.

7 Véase el artículo 393, IV, del Código Penal de ese Estado.

8 El ámbito de aplicación del Código Penal Federal en materia de aborto es hoy notablemente acotado, pero sería un error ignorarlo. Su alcance y su relación con las legislaciones estatales tiene que ver con la evolución de la posición constitucional del DF. Antes de 1999, el DF carecía de un cuerpo legislativo propio y en su ámbito se aplicaba el Código federal, que contenía un catálogo muy exhaustivo de delitos y penas precisamente porque en el DF hacía las veces de regulación penal "en materia común" (esto es, de fuero local, no federal). Hoy en día el DF ya cuenta, como los Estados, con un código propio, con su regulación propia sobre el aborto y la contenida en el Código federal ya no le es aplicable. Sin embargo, esta última mantiene su vigencia en lo que se considera "territorio federal": las sedes de las instituciones federales, los buques y aeronaves, las sedes diplomáticas y, de modo muy relevante, la red de hospitales de la Federación -los que dependen de la Secretaría de Salud y los que integran los sistemas de seguridad social. 
legislativa aprobó cuatro cambios importantes: en primer lugar, disminuyó la pena para el delito de aborto y eliminó las atenuantes por motivos de "honor"; en segundo lugar, añadió a las causas de despenalización existentes (aborto imprudencial, peligro para la vida de la madre y violación) tres nuevas hipótesis: la interrupción de un embarazo producto de una inseminación artificial no consentida, la interrupción de un embarazo cuya continuación representa una amenaza grave para la salud de la mujer, y el aborto de productos con alteraciones genéticas o congénitas que puedan poner en riesgo su supervivencia; en tercer lugar, especificó el tipo de información que los médicos deben proporcionar a la embarazada en las hipótesis no sancionables; finalmente, reformó el Código de Procedimientos Penales, para detallar cómo el Ministerio Público podría proceder a autorizar un aborto tras haber recibido una denuncia por delito de violación ${ }^{9}$.

Parte de esta reforma fue impugnada poco después ante la Corte por una minoría parlamentaria y declarada esencialmente válida en una sentencia emitida en enero de 2002. Vale la pena detenerse brevemente en esta resolución, pues muchos de los argumentos manejados en las demandas que originaron el proceso del 2008 no se entienden sin este antecedente, aunque su influencia en la sentencia de agosto pasado parece haber sido, finalmente, muy tenue.

\section{La sentencia del 2002 (Aborto I)}

En el proceso se cuestionaba la no punibilidad del aborto en casos que involucraran fetos con graves malformaciones, así como la regulación de la intervención del Ministerio Público en los casos de violación o inseminación artificial no consentida. La no punición del aborto cuando la continuación del embarazo pusiera en riesgo la salud de la madre, uno de los puntos centrales de la reforma, no fue impugnada.

La sentencia comienza desarrollando la distinción entre "excluyentes de responsabilidad" y "excusas absolutorias"10 y aborda dos argumentos aparentemente periféricos, pero que gozan de una tradición inmensa en México: el que denunciaba la falta de adecuada "fundamentación y motivación" de la ley, y el que denunciaba la violación de los principios de seguridad jurídica y el principio de "exacta aplicación de la ley penal"11. La Corte, en cualquier caso, los desestimó con rapidez ${ }^{12}$ y pasó a desplegar un razonamiento que constó de dos grandes partes: en la primera se sostuvo que tanto el derecho a la vida como el "producto de la concepción" gozan de una protección clara y fuerte en el ordenamiento jurídico mexicano, derivada de lo dispuesto en la Constitución, los tratados y las leyes ordinarias; en la segunda se señaló que, pese a ello, las normas impugnadas eran constitucionales porque simplemente preveían una causa de exclusión de punibilidad y no de exclusión de responsabilidad, esto es, casos excepcionales de no imposición de pena, pero que dejaban intocado el carácter antijurídico de la conducta y en esa medida -debe entenderse- seguían rindiendo protección al concebido.

9 La reforma fue publicada en la Gaceta Oficial el 24 de agosto del 2000.

10 La relevancia de este desarrollo sólo se alcanza a ver en la parte final de la resolución y es sin duda allí donde debería haberse realizado.

11 Los artículos 14 y 16, que prevén esencialmente garantías de forma y procedimiento y que además funcionan como punto de contacto (y confusión) entre "constitucionalidad" y "legalidad", han sido objeto de un desarrollo jurisprudencial desproporcionado. Centrar el litigio constitucional en estas previsiones ha permitido tradicionalmente al poder judicial evitar pronunciamientos sobre derechos "sustantivos" y aminorar sustancialmente la eficacia del control de la constitucionalidad de leyes y sentencias.

12 Suprema Corte de Justicia de la Nación. Acción de inconstitucionalidad 10/2000, de 29 y 30 de enero de 2002, pp. 80-84. La denominación Aborto I (al igual que Aborto II, que usaremos más adelante) no es oficial, sino un recurso expositivo para hacer más ligera la reiteración de referencias. 
Efectivamente, y a pesar de lo aparentemente poco promisorio del texto constitucional al respecto, la Corte estimó que los artículos 14 (que en esos momentos disponía que nadie puede ser privado de la vida, la libertad o las propiedades sin juicio previo seguido con respeto a las formalidades esenciales del procedimiento y conforme a leyes expedidas con anterioridad al hecho) y 22 (que especificaba en qué casos podía imponerse la pena de muerte) eran base suficiente para declarar que la Carta Magna "protege toda manifestación de vida humana, independientemente del proceso biológico en el que se encuentre" ${ }^{\prime 13}$. Junto a ello se otorgó un gran protagonismo a dos preceptos que se convertirían desde ese momento en ingredientes prominentes del debate mexicano sobre el aborto: los artículos $4^{\circ}$ y 123 de la Constitución Federal. De los varios contenidos del primero se destacó, curiosamente, no el derecho de las personas "a decidir respecto del número y espaciamiento de sus hijos", sino el párrafo que protege el derecho a la salud, del cual se extrajo la necesidad de proteger tanto a la mujer como al concebido en cualquier momento de su desarrollo ${ }^{14}$. En cuanto al artículo 123, la Corte consideró que la mención específica a ciertos derechos de las embarazadas en el ámbito laboral debía leerse como un testimonio de la voluntad constitucional de proteger la vida desde el momento de la concepción ${ }^{15}$. La reconstrucción de las fuentes se cerró con varias alusiones a leyes ordinarias y con una interpretación escasamente menos arriesgada de la Convención sobre los Derechos del Niño: tomando como base una alusión del Preámbulo a la necesidad proteger a los niños "tanto antes como después" del nacimiento, la Corte concluye que la Convención obliga a México a proteger la vida humana desde la concepción ${ }^{16}$.

Con independencia de la mayor o menor solidez de la primera parte del argumento, Aborto I destaca por el carácter elusivo de la segunda (y brevísima) parte del mismo y por lo tenue del vínculo entre ambas. En efecto, concluida la reconstrucción dogmática sobre el derecho a la vida, la sentencia simplemente destaca que lo único que la legislación examinada prevé es la no imposición de la pena en una situación peculiar, excepcional y dramática para la mujer embarazada; se destacó que la disposición "no establece que se deba privar de la vida al producto de la concepción sino sólo que de haberse producido la muerte en esas circunstancias y habiéndose llenado los requisitos, no procederá imponer la sanción" ${ }^{17}$. La Corte considera que, por los mismos motivos, no se transgrede el principio de igualdad: la ley no establece en realidad que a determinados concebidos, por sus características, deba privárseles de la vida ${ }^{18}$, sino que sencillamente permite a un juez no aplicar en ciertos procesos penales la sanción prescrita para el delito.

La sentencia del 2002 es, entonces, una resolución que avanza trepidante hacia una conclusión final sin explicar exactamente qué es lo que autoriza a alcanzarla: decreta que las normas impugnadas no afectan la protección del concebido sin justificar por qué la introducción de una excusa absolutoria no opera tal afectación; declara que el concebido sigue protegido sin explicar por qué

13 Ibíd., p. 87. Según la Corte, "el artículo 14 constitucional reconoce como derecho fundamental inherente a todo ser humano el derecho a la vida y protege este derecho de manera general, es decir, protege toda manifestación de vida humana, independientemente del proceso biológico en que se encuentre" (p. 87). Las previsiones del artículo 22 confirmarían lo anterior: en la medida en que la imposición de esta pena se prevé con carácter excepcional y en los confines de un catálogo cerrado de casos, se considera posible concluir que la Constitución protege la vida como "derecho supremo del ser humano, sin el cual no cabe la existencia y el disfrute de los demás derechos" (p. 90).

14 Ibíd., pp. 92-97.

15 Ibíd., pp. 100-103. La sentencia se refiere también a los artículos $1^{\circ}$ (principio de igualdad) y 17 (principios rectores de la administración de justicia) pero estima -sin duda correctamente- que no son determinantes en la reconstrucción de la posición constitucional del derecho a la vida.

16 Ibíd., pp. 104-106.

17 Ibíd., pp. 110-111.

18 Ibíd., pp. 111-112. La acción fue desestimada respecto de las normas que disciplinaban la actuación del Ministerio Público en casos derivados de violación. Seis ministros votaron por su inconstitucionalidad, no la supermayoría de ocho requerida para anular la ley. 
la tipificación no ve mermada su virtualidad protectora en el nuevo esquema; sitúa al concebido en un alto pedestal constitucional, pero no extrae de ello casi ninguna consecuencia. La ausencia de un razonamiento en el que esta protección se contraponga y pondere con otros ingredientes constitucionales y la ambigüedad del pronunciamiento, hace difícil extraer la ratio de la decisión. La sentencia, hay que decirlo, no hace mención alguna a los derechos de las mujeres en materia sexual y reproductiva, o su derecho a la privacidad o a la salud: se refiere exclusivamente al derecho a la vida y a la no discriminación del embrión-feto en un contexto -paradójicamente y se reconoce en la resolución- en el que entran en juego solo de modo marginal, pues se trata de casos que por definición involucran a fetos con muy pocas posibilidades de sobrevivir ${ }^{19}$.

La sentencia resintió también las dificultades derivadas del hecho de que las "tesis" de ella derivadas fueran aprobadas por un juego de mayorías y minorías distinto al que apoyó la sentencia misma, lo que oscureció el grado de vinculancia real de sus contenidos ${ }^{20}$.

\section{Cambios legales y el camino hacia la sentencia del 2008}

La ambigüedad de Aborto I, tanto en alcance como en fuerza vinculante, fue profundizada a mi juicio por dos cambios importantes, uno legislativo y otro constitucional.

En enero del 2004 el legislador del DF añadió a la Ley de Salud una regulación sobre la objeción de conciencia de los médicos en casos de aborto e introdujo dos cambios en el Código Penal: se modificaron los años de cárcel imponibles en ciertas circunstancias, y las hipótesis que hasta el momento eran meras "excusas absolutorias" pasaron a calificarse como "excluyentes de responsabilidad". La reforma no fue impugnada ante la Corte, pero es fácil percibir su inmensa relevancia: el argumento que (mal que bien) había sustentado en Aborto / la constitucionalidad de la ley era, como hemos visto, que en su contexto el aborto continuaba siendo una "conducta antijurídica" cuya comisión autorizaba la apertura de un proceso penal, matizado sólo por causas de no imposición de la pena en casos muy excepcionales y sujetos a importantes cargas probatorias. Nada de ello podría volver a ser dicho respecto de esas normas a partir de la reforma del 2004.

Otras de las premisas de Aborto I quedaron afectadas por la reforma de diciembre de 2005 a los artículos 14 y 22 de la Constitución. Del primero desapareció la mención a la posibilidad de privar a los ciudadanos de la "vida" en ciertas condiciones ${ }^{21}$, y el artículo 22 pasó a incluir a la pena de muerte en el catálogo de penas prohibidas. Ambos cambios, según queda sobradamente expuesto en las constancias parlamentarias, se ligaban al debate sobre la pena de muerte, no al debate sobre el aborto: se quería, según se dijo, desterrar esta pena del ordenamiento a la vista de su ineficacia para combatir el crimen y en consonancia con un compromiso por reforzar la

19 Es difícil, en definitiva, saber si la débil trabazón entre las tesis sobre la protección constitucional del concebido y el reconocimiento de validez de normas que le retiran parte de su protección penal debe leerse como una evidencia de que la Corte considera a la primera intocable o, por el contrario, banal y prácticamente exenta de consecuencias.

20 En México se extraen fragmentos de la sentencia para aislar y difundir su ratio decidendi. Se les llama "tesis" y las mismas (en el contexto de una acción de inconstitucionalidad) son "jurisprudenciales" si reflejan decisiones adoptadas por al menos ocho votos y "aisladas" en caso contrario. En Aborto I, la declaración de validez de la ley penal fue apoyada por una mayoría de 7 votos (de 11), pero el texto concreto de varias de las tesis, sometidas a votación con posterioridad, concitó el apoyo de entre 9 y 10 votos (lo cual las convertía en tesis "jurisprudenciales" según las reglas generales). Más allá de adecuación o inadecuación de este proceder, la variabilidad se explica, sin duda, por el hecho de que las tesis contienen todavía menos ratio decidendi que la resolución misma: algunas de ellas describen la posición constitucional del concebido y otras describen los contenidos de la ley enjuiciada y destacan qué figura de la dogmática penal contienen, pero ninguna explica por qué debe concluirse que la previsión de excusas absolutorias no merma el mandato constitucional de protección a la vida previamente hallado por la Corte.

21 A partir de la reforma, de lo único que pueden ser privados, en ciertas condiciones, es de "la libertad o de sus propiedades, posesiones o derechos". 
política de derechos humanos y homologar la normativa con los tratados internacionales suscritos por México. No obstante, fueran cuales fueran las motivaciones, es indiscutible que la reforma alteró algunas de las premisas básicas del debate constitucional sobre el aborto. A partir del 2005 la única mención literal significativa a la "vida" en la Constitución mexicana desaparece ${ }^{22}$; por otro lado, sin embargo, emerge una prohibición expresa de la pena de muerte destinada también a tener juego en la articulación jurídica del debate.

En estas condiciones se abría en el 2007 la tramitación de lo que se convertiría en la reforma de abril de 2007 al Código Penal y a la Ley de Salud del DF ${ }^{23}$. La reforma rompía con el modelo heredado porque pasaba a definir el aborto como "la interrupción del embarazo después de la duodécima semana de gestación", entendiendo por embarazo, además, "la parte del proceso de reproducción humana que comienza con la implantación del embrión en el endometrio" (artículo 144 CPDF). Se trataba, sin duda, de una manera de enfatizar la retirada total y absoluta del derecho penal del ámbito de las interrupciones tempranas del embarazo que, aun sin dejar de incurrir en ciertos costos en términos de técnica legislativa (por su convivencia con la tipificación del "aborto forzado"24), era congruente con el segundo pilar de la reforma: los cambios en la Ley de Salud orientados a poner en marcha la prestación de servicios de consejería previos y posteriores a la interrupción del embarazo y a la práctica gratuita de ésta en los hospitales del Gobierno de la ciudad (artículo 16 bis 8 LSDF). La reforma cerraba con una rebaja considerable de la pena imponible a las mujeres que se practiquen o se hagan practicar un aborto en los casos (ahora siempre posteriores al primer trimestre) en que no concurran causas de exclusión de responsabilidad ${ }^{25}$.

\section{Los cargos contra la ley del Distrito Federal}

A finales de mayo de 2007 el Procurador General de la República y el Presidente de la Comisión Nacional de los Derechos Humanos (CNDH) interpusieron sendas acciones de inconstitucionalidad contra las reformas anteriores, argumentando que infringían el reparto de competencias constitucionalmente establecido, vulneraban el derecho a la vida del concebido, discriminaban al progenitor masculino y a los embriones menores de tres meses, desconocían las exigencias implícitas en los principios de legalidad y seguridad jurídica y vulneraban el derecho a la objeción de conciencia ${ }^{26}$. Su admisión no obstaculizó la organización de los servicios de asesoría e interrupción

22 Hay, ciertamente, otras menciones a la "vida" en la Constitución ("vida comunitaria", "vida privada", "sistema de vida", etcétera) que, aunque hubo quien las sacara a colación en el debate reciente, parece obligado calificar de no relevantes para la reconstrucción de la posición jurídica del concebido.

23 Véase en LAMAS, M. La despenalización del aborto en la Ciudad de México, Debate Feminista Nº 38: pp. 3-8; octubre de 2008, un breve recuento del proceso de presentación y discusión de iniciativas legislativas que antecedió a la aprobación de la reforma.

24 El artículo 146 define el "aborto forzado" como toda "interrupción del embarazo, en cualquier momento, sin el consentimiento de la mujer embarazada" y lo castiga con una pena de entre 5 y 10 años de prisión. Parece, en efecto, abiertamente mejorable la opción de definir por un lado "aborto" como la interrupción posterior a la duodécima semana de gestación (lo cual nos sugiere naturalmente un escenario conceptual de "no aborto" con anterioridad a esa fecha) y por otro usar "aborto forzado" para hacer referencia a las interrupciones tanto anteriores como posteriores a las 12 semanas cuando no cuentan con el consentimiento de la embarazada. La contradicción normativa se evita porque se trata de dos definiciones estipulativas cuyos referentes explícitos ciertamente permiten derivar reglas no contradictorias, pero sólo a costa de dejar de lado el uso general de la distinción entre género y especie y su reflejo en el uso de sustantivos y adjetivos calificativos.

25 De una pena de entre 1 y 3 años de prisión se pasa a una de entre 3 y 6 meses de prisión o entre 100 y 300 días de trabajo en favor de la comunidad (artículo 145 CPDF).

26 Suprema Corte de Justicia de la Nación. Acciones de inconstitucionalidad 146/2008 y 147/2008, de 28 de agosto de 2008. La acción es una vía de control abstracto de la constitucionalidad de la ley que permite a una serie acotada de actores institucionales, en el plazo de un mes desde la publicación, solicitar su declaración de invalidez con efectos 
del embarazo, pero avivó la movilización social en torno a la ley. Veamos con más detenimiento lo planteado en dos demandas muy similares y de estructura algo contraintuitiva ${ }^{27}$.

Las demandas comenzaban denunciando la vulneración de los derechos a la vida y a la salud del concebido, derivados -se aducía- de lo dispuesto por los artículos 14, 22, 123 y $4^{\circ}$ de la Constitución y por la disposición transitoria tercera de una reforma constitucional de 1997 en materia de nacionalidad.

Para los actores las reformas relacionadas con la pena de muerte constituían la prueba fundamental de la protección máxima del derecho a la vida en la Constitución, con independencia de que su resultado directo fuera, de hecho, su desaparición del texto constitucional: si ahora el artículo 14 no mencionaba la vida, se debía a que su protección se había trasladado al artículo 22; al prohibir éste la pena de muerte sin ningún tipo de calificación o condición, resultaba claro que protegía la vida como derecho y valor supremo. Los argumentos relacionados con el artículo 123 y el artículo $4^{\circ}$-salud (y la correspondiente ausencia del artículo $4^{\circ}$-derechos reproductivos), que podrían parecer tan sorprendentes e indirectos a primera vista, resultan por el contrario previsibles para los conocedores de la sentencia del 2002: como la propia Corte había subrayado, se trataba del vínculo entre los derechos laborales de la mujer embarazada y la garantía del derecho a la salud, por un lado, y la proposición según la cual el concebido está en todo momento constitucionalmente protegido y puede calificarse de titular del derecho fundamental a la vida, por otro. El último engarce constitucional intentado en las demandas es todavía más indirecto y constituye, de nuevo, un argumento sobre implícitos: dado que el transitorio tercero de la reforma constitucional de 1997 establece que las reglas sobre adquisición y pérdida de la nacionalidad mexicana vigentes hasta el momento serían de aplicación a los concebidos bajo su vigencia, señalaban los actores, es evidente que el poder reformador de la Constitución claramente consideraba que el nasciturus es una persona, al que debe reconocerse la protección constitucional que en esa calidad le corresponde.

Junto a este "núcleo de la vida", las demandas presentaban cuatro argumentos más centrados en otros derechos o en otros titulares de derechos. En primer lugar, se argumentaba que las normas impugnadas vulneraban el derecho a la procreación de los hombres (artículo $4^{\circ}$ ) y los trataba discriminatoriamente (artículo $1^{\circ}$ ). El derecho a la procreación, se subrayaba, pertenece a la pareja y es de ejercicio conjunto; una vez que se ha ejercido, el derecho de la mujer a decidir acerca del número y espaciamiento de sus hijos le impone obligaciones respecto del concebido y del progenitor masculino. Si llega a surgir un conflicto entre la voluntad de la madre y la del padre, argumentaba la CNDH, sería necesario "ponderar" las dos para llegar a una solución conjunta. La legislación impugnada, en cambio, excluía arbitrariamente la participación del padre al respecto.

generales. La acción fue creada en 1994 y es una novedad notable en un sistema de control de constitucionalidad construido sobre el entramado fundamental del juicio de amparo. El amparo permite el control de la constitucionalidad de la ley a instancia de cualquier ciudadano con interés legítimo tanto con motivo de su entrada en vigor, como al producirse un acto de aplicación, pero conduce solamente a dejar sin aplicación la ley en el caso concreto.

27 Es raro, por ejemplo, que los argumentos sobre incompetencia de la Asamblea, o sobre los problemas de inseguridad jurídica planteados por las normas, se desarrollen con posterioridad a los centrados en el derecho a la vida cuando, de ser fundados, harían innecesario un estudio de constitucionalidad desde la perspectiva de los derechos. Por otro lado, la demanda de la CNDH inicia con tres conceptos de invalidez dedicados a reconstruir, respectivamente, la posición jurídica del "derecho a la vida del producto de la concepción", del "derecho a la vida" y del "derecho a la protección del proceso de gestación". Lo forzado de esta fragmentación se refleja en una argumentación repetitiva y destrabada; el segundo de estos rubros, por ejemplo, resulta que se distingue del primero no por el objeto de la protección jurídica (o por el titular del derecho en que se pone el acento), sino por el tipo de fuente en que se busca la protección: los convenios de derechos humanos versus las normas de emisión interna. En lo que sigue tomamos como referencia básica la demanda de la CNDH. 
El principio de igualdad (artículo $1^{\circ}$ ) se hacía jugar en dos direcciones adicionales: discriminación dentro del universo de los embriones-fetos y discriminación dentro del universo de las mujeres. Lo primero, señalaban, ocurría porque el legislador introducía una diferenciación por razón de edad, al distinguir entre concebidos de más y menos de doce semanas sin atender a criterios objetivos y razonables. La apelación a los mayores riesgos para la salud de la madre en las interrupciones posteriores a esa fecha no constituía, a juicio de los actores, un punto capaz de modificar la anterior conclusión. Lo segundo -la discriminación de las mujeres por razón de edad- se producía porque la ley no regulaba expresamente los abortos de las menores de edad, olvidando que no pueden otorgar consentimientos jurídicos válidos al carecer de capacidad jurídica de ejercicio y desconociendo las prerrogativas de los titulares de la patria potestad, que pueden incurrir en responsabilidad por motivos relacionados con lo que las primeras hagan o resientan.

El alegato centrado en la seguridad jurídica y el principio de legalidad (o de "exacta aplicación de la ley penal") denunciaba por su parte varias imprecisiones y ambigüedades. La ley, se decía, penalizaba interrupciones posteriores a las doce semanas de embarazo sin que haya manera de determinar cuándo empieza ese plazo (pues tampoco hay manera de determinar con exactitud cuándo se produce la implantación del embrión en el endometrio), y hace referencia al "consentimiento de la mujer", sin especificar cómo debe exteriorizarse o cómo deben evitarse los vicios en su formación. Por otro lado, los actores denunciaban indeterminaciones ligadas al carácter elusivo de los bienes jurídicos protegidos por las normas impugnadas, a la vista de la diferencia entre la pena imponible a la mujer y la prescrita para terceros intervinientes y de la segmentación del embarazo en tres etapas ${ }^{28}$.

El argumento sobre la falta de competencia del legislador del DF señalaba esencialmente que el artículo 144 del CPDF incluía una definición de "embarazo" incompatible con las disposiciones federales en materia de salud, a las cuales correspondía reconocer preeminencia en los términos del sistema constitucional vigente.

Finalmente, las demandas vertían argumentos contra las previsiones de la Ley de Salud y denunciaban su incompatibilidad con la violación al derecho a la objeción de conciencia que estimaban protegido en los artículos 6 y 24 de la Constitución mexicana y 12 y 13 de la Convención Americana. Los actores interpretaban que, al referirse la norma sobre objeción a los "casos permitidos" de interrupción del embarazo, quedaba limitada a los casos de exclusión de responsabilidad previstos en el artículo 148 del CPDF y obligaba por tanto a los funcionarios del DF a practicar abortos durante el primer trimestre -período durante el cual, en los términos de la nueva ley, no podía hablarse de "aborto permitido", sino sencillamente de "no aborto".

Hasta aquí los cargos. Todos ellos encontraron un primer contrapunto en las extensas contestaciones o "informes" elevados a la Corte por la Asamblea Legislativa del DF ${ }^{29}$. ¿Cómo los abordaron los ministros? En el apartado siguiente sintetizamos los principales puntos de la argumentación de la mayoría. La discusión del Pleno, debemos aclarar, se articuló en un principio en torno a un "proyecto de resolución" elaborado por Sergio Aguirre Anguiano, cuyas tesis fueron rechazadas

28 Las demandas señalaban que el hecho de que la ley castigue a quienes auxilien a la mujer a abortar con más severidad que a esta última les creaba incertidumbre respecto del bien jurídico que podría resultar protegido mediante sanciones tan desproporcionadamente bajas; además, aducían que la segmentación del embarazo en tres etapas (antes de la implantación del embrión en el endometrio, después de ese punto y después de las primeras doce semanas) parecía sugerir la protección de bienes jurídicos distintos en cada etapa del mismo, e imaginar escenarios de concurso de delitos de lesiones, aborto y homicidio en ciertas circunstancias.

29 Omitimos mayor referencia a ellos porque son muy largos y no son imprescindibles para entender el contenido de la sentencia; en cualquier caso hay una síntesis de los mismos en la resolución (Suprema Corte de Justicia de la Nación. Acciones de Inconstitucionalidad 146/2008 y 147/2008, de 28 de agosto de 2008, pp. 49 a 76). 
muy pronto por la mayoría de sus colegas. Sin embargo, en lugar de que ello propiciara el retorno del asunto y la presentación de un proyecto distinto por otro Ministro, y sin duda persuadidos de que contaban ya con los elementos necesarios para una toma directa de posición, los Ministros procedieron a discutir y votar el asunto sin un texto de apoyo y encargaron a uno de ellos (José Ramón Cossío) la elaboración posterior de un texto que recogiera el sentir de la mayoría. Este proceso -que en México se conoce como la elaboración del "engrose" de la sentencia- retrasó más de cuatro meses la emisión de la resolución ${ }^{30}$.

\section{La sentencia del 2008 (Aborto II)}

Tras descartar el análisis de algunas cuestiones por motivos de procedencia -entre ellas las que tenían que ver con objeción de conciencia ${ }^{31}$ - la parte considerativa de la sentencia del 2008 se divide en tres apartados, el primero dedicado a cuestiones de competencia, el segundo centrado en las denuncias de infracción de derechos y el tercero consagrado a los problemas relativos a los principios de legalidad penal y seguridad jurídica.

El extenso desarrollo inicial acerca del reparto de competencias en materia de "salud" y "salubridad general" y del tipo de espacios que deja para la legislación penal estatal resulta interesante fundamentalmente para una audiencia interna y no nos detendrá mucho. Baste apuntar que la Corte perfila una competencia federal muy robusta en materia de "salubridad general" (en la cual se estima incluida la de "salud"), en cuyo contexto es la Ley General de Salud federal la que tiene la facultad de organizar la "concurrencia" de las autoridades federales, estatales y municipales en la materia, aunque la Corte descarte hablar de una vinculación "en bloque" de los Estados a todo tipo de reglamentación federal. Esta acusada federalización no tiene, sin embargo, grandes consecuencias en el caso, porque la definición de "embarazo" a la que se contraponía la del CPDF no está en la Ley General, sino en un Reglamento específico sobre investigación. Igualmente, se indicó -y sin duda éste es el punto que hay que considerar central para la desactivación de las impugnaciones- que las normas analizadas se beneficiaban de lo que la sentencia llamó la "autonomía calificadora" del derecho penal: la capacidad de las normas penales de definir estipulativamente los conceptos relevantes en su marco ${ }^{32}$.

Tampoco es necesario detenerse mayormente en la tercera parte de la argumentación -igualmente extensa-, que incorpora un desarrollo dogmático sobre las nociones de tipicidad, legalidad y proporcionalidad de las penas en el orden jurídico mexicano. El pronunciamiento específico en este punto subraya que las normas impugnadas contienen todos los elementos necesarios para cumplir su función ante los ciudadanos y guiar su aplicación, y que los bienes jurídicos por ellas protegidos son los mismos que antes de la reforma: la vida en gestación y la libre determinación

30 Este sistema de elaboración de resoluciones ha sido objeto de críticas muy entendibles. La separación entre debate, votación y emisión final de la resolución (que debe reflejar en texto los resultados de la primera, y que por tanto puede ser muy distinta al texto inicialmente discutido) siembra dudas acerca del alcance de la decisión, permite cambios de última hora y dificulta el debate público sobre la sentencia. Véase, sobre este punto, ELIZONDO, C. y MAGALONI, A. L. Cómo decide la Corte. Nexos N³67: pp. 57-63; septiembre 2008. La dispersión de las fuentes de la decisión aumenta por el hecho de que la publicación de los votos particulares y concurrentes no tenga que ser simultánea a la de la resolución y por el hecho de que la extracción y publicación de las "tesis" sea siempre bastante posterior.

31 Los artículos sobre objeción de conciencia estaban en la Ley de Salud desde el 2004, y la última reforma no los había modificado. Sin embargo, los actores sostenían que la última reforma revivía la posibilidad de impugnarlos porque, al modificar artículos relacionados, alteraban su contenido normativo. La Corte estima que la referencia de la norma a los "casos permitidos" abarca a las interrupciones que, por practicarse en el primer trimestre, no constituyen aborto, pero por lo demás considera extemporánea la impugnación (Acciones de Inconstitucionalidad 146/2008 y 147/2008, de 28 de agosto de 2008, pp. 103-107).

32 Ibíd., pp. 133-152. 
de la voluntad de la mujer (en tanto la presencia o ausencia de su consentimiento es relevante y existen previsiones especiales sobre el uso de la violencia) ${ }^{33}$.

¿Qué se dice, entonces, sobre las cuestiones de derechos que protagonizaban las demandas? La sentencia les da respuesta en tres partes. En primer lugar, analiza el grado de protección del bien o derecho a la vida en el ordenamiento mexicano y en segundo lugar se extiende sobre los deberes, prohibiciones y facultades del legislador democrático (en el marco de la Constitución) para penalizar y despenalizar conductas, hasta llegar a la conclusión de que, estando las normas impugnadas dentro del ámbito en que la penalización es facultativa, no obligatoria, la opción tomada por el legislador del DF no puede estimarse reprochable. Finalmente, la Corte desestima brevemente los argumentos según los cuales las normas impugnadas todavía ameritarían invalidación por ser discriminatorias.

La argumentación sobre la vida avanza fundamentalmente en forma de refutación de las tesis defendidas en las demandas ( $y$, hay que decirlo, de las contenidas en el proyecto de sentencia elaborado por el Ministro Aguirre, que hablaba de un derecho a la vida del concebido, le reconocía un carácter absoluto y lo declaraba inmune a cualquier tipo de regulación) ${ }^{34}$. Así, y subrayado de inicio que el derecho a la vida no está plasmado expresamente en ningún punto del articulado, la sentencia desvirtúa el argumento según el cual debe reconocérsele un carácter básico y preeminente por ser "presupuesto" de la existencia y ejercicio de todos los demás (la Corte explora las consecuencias buscadas y no buscadas de sostener tal posición), el argumento según el cual sería un derecho absoluto (la Corte señala que ningún derecho lo es) y el argumento según el cual los artículos 14 y 22 reflejarían su protección constitucional máxima. La Corte señala la dificultad de extraer una proposición tan potente por una vía tan indirecta y lo complicado de apelar a las "verdaderas intenciones" del constituyente al regular un punto acotado -la pena de muerte- cuando sus intenciones expresadas se refieren a cuestiones totalmente distintas (la ineficacia preventiva de esta pena, o las condiciones exigidas para la firma del Estatuto de Roma) ${ }^{35}$.

La Corte dedica un apartado comparativamente muy extenso a refutar la interpretación de los tratados de derechos humanos presentada en las demandas, mostrando que, aunque la protección del derecho a la vida es uno de sus contenidos centrales, ninguna de sus previsiones ni ninguno de los pronunciamientos sus órganos de supervisión y garantía lo entiende como un derecho absoluto o define a partir de qué momento exacto debe protegerse la vida humana. Aunque la sentencia no hace eco de ello, la Corte adopta una interpretación de la Convención de los Derechos del Niño opuesta a la acogida en Aborto l, y reconstruye el significado de la declaración interpretativa que México realizó respecto del primer párrafo del artículo $4^{\circ}$ de la Convención Americana (que

33 Ibíd., pp. 191-206.

34 Es difícil exagerar lo insólito de la posición contenida en el proyecto de resolución inicialmente sometido a discusión. El proyecto sostenía que, aunque normalmente las cuestiones de competencia están llamadas a anteceder el análisis de las normas por motivos de contenido (hay que ver si la autoridad tiene competencia para dictar norma alguna en el ámbito que interesa, antes de pasar a examinar si las mismas respetan o no los límites de contenido que les imponen otras normas del ordenamiento) en realidad en el caso debía reconocerse la interdependencia de las mismas, y aun la prelación de la segunda sobre la primera. Por ello exploraba en primer término la posición del derecho a la vida en el ordenamiento mexicano, llegaba a la conclusión de que gozaba de una protección absoluta que impedía que fuera objeto de regulación y concluía que las normas impugnadas eran inválidas por ausencia de competencia regulatoria de la Asamblea del DF. Este proyecto está disponible en www.informa.scjn.gob.mx [consultada el 12 de diciembre de 2008].

35 Acciones de Inconstitucionalidad 146/2008 y 147/2008, de 28 de agosto de 2008, pp. 153-158. 
establece que las partes deben proteger el derecho a la vida "en general, desde el momento de la concepción" $)^{36}$.

Llegados a este punto, la argumentación deja de avanzar a ritmo de refutación de lo que las demandas pretenden que la Constitución diga, y pasa a hacer unas referencias breves y algo crípticas a lo que la Constitución de hecho dice (según la Corte): "la Constitución", se señala, "no reconoce un derecho a la vida en sentido normativo" sino que obliga más bien al Estado a promocionar las condiciones para su adecuado disfrute una vez que existe ${ }^{37}$; pero también se acepta "la existencia de un bien constitucional e internacionalmente protegido [la vida] en los términos hasta ahora expuestos", extremo que en cualquier caso no es determinante porque la Corte no encuentra "ningún fundamento constitucional o internacional para un mandato de penalización de su afectación que permitiera sostener que existe una obligación del legislador para el establecimiento o mantenimiento de un tipo penal específico" ${ }^{\prime 38}$.

A continuación, la resolución se sumerge en lo que sin duda hay que considerar su ratio decidendi fundamental, en la que se delimita el margen de maniobra que la Constitución otorga al legislador democrático para penalizar o despenalizar conductas. El punto de partida es que "la mera existencia de un derecho fundamental no implica la obligación de la penalización de una conducta que lo afecte" ${ }^{\prime 39}$. Lo determinante para el juicio de constitucionalidad en este punto es, por el contrario, ver si la Constitución o los tratados imponen una obligación o una prohibición de penalización respecto de las cuestiones relevantes; si no es así, el legislador es libre para determinar cuándo debe entrar en juego el derecho penal y cuándo debe retirarse, con el solo límite de no poder criminalizar o despenalizar de forma discriminatoria, ni usar leyes privativas (no generales) ni hacerlo sin seguir los procedimientos prescritos ${ }^{40}$.

La sentencia destaca que, a diferencia de lo ocurrido en otros litigios sobre el aborto en el derecho comparado, la litis no obligaba a examinar si una determinada penalización de conductas respeta los derechos fundamentales, sino si el legislador estaba obligado a penalizar una conducta específica ${ }^{41}$. La sentencia refiere casos históricos de despenalización de conductas que han dejado de merecer reproche social y que no son controvertidos, y señala que el legislador del DF parece haber hecho algo similar en un caso en el que no existe una obligación constitucional expresa de penalizar ${ }^{42}$. A continuación, puso énfasis en el conjunto de razones invocadas por el legislador en apoyo de las normas impugnadas: el modo en que la legalización del aborto temprano se consideró necesaria para combatir los problemas de salud pública asociados al aborto clandestino, la voluntad de mejorar los servicios disponibles para las mujeres de menos ingresos, trabajando por la igualdad en el disfrute de los derechos sexuales y reproductivos, o la voluntad de concentrar las interrupciones cuando representan un riesgo bajo para la salud de la mujer y el desarrollo de las facultades sensoriales y cognitivas del concebido todavía no se ha producido ${ }^{43}$. Concluyó indicando que esta ponderación de factores que condujo al legislador a la

36 Ibíd., pp. 158-174. La declaración interpretativa dice así: “con respecto al párrafo 1 del artículo 4, considera que la expresión 'en general' usada en el citado párrafo no constituye obligación de adoptar o mantener en vigor legislación que proteja la vida 'a partir del momento de la concepción' ya que esta materia pertenece al dominio reservado de los Estados".

37 Ibíd., p.175.

38 Ibíd., p. 175.

39 Ibíd., p. 176.

40 Ibíd., p. 180.

41 Ibíd., pp. 176-177.

42 Ibíd., pp. 179-180.

43 Ibíd., pp. 180-182. 
despenalización no encuentra obstáculo constitucional expreso y puede considerarse una medida idónea para salvaguardar "la libertad de las mujeres [para decidir] respecto de su cuerpo, de su salud física y mental e, incluso, respecto de su vida" ${ }^{44}$. La Corte señala además que en el caso analizado la pena no sirve para asegurar la protección del proceso de gestación, y que se trata de normas que operan como instrumento simbólico y no como una herramienta eficaz, aunque siempre de ultima ratio, como debe ocurrir en una democracia ${ }^{45}$.

La sentencia dedica las páginas finales del bloque que comentamos a desechar los argumentos que denunciaban la violación de los derechos reproductivos y la igualdad de los hombres, así como los señalamientos relativos a las menores de edad. Respecto a lo primero, la Corte destaca esencialmente que la desigual posición de hombres y mujeres en el momento de tomar la decisión acerca de la interrupción responde a la asimetría de lo que para cada uno de ellos va a significar la continuación del embarazo y la crianza del hijo; dado que lo que el derecho determina es quién puede vetar la decisión de quién, se estima razonable dar la decisión final a la mujer porque el sentido de la misma tendrá consecuencias para ella que no son comparables con las experimentadas por terceros (los participantes masculinos u otros); la posibilidad de reclamar judicialmente una contribución al mantenimiento del menor, se señala, es demasiado incierta e imperfecta para considerar que anula la asimetría señalada ${ }^{46}$.

En cuanto a la ausencia de un tratamiento específico para las menores de edad, la Corte no lo considera un motivo de inconstitucionalidad: las reglas generales sobre consejería y consentimiento informado contenidas en la Ley de Salud, destaca, son extensas, detalladas y en su contexto las menores son mencionadas como sujetos de especial atención, y dan cobertura por tanto a las especiales necesidades de los casos que las involucren ${ }^{47}$.

\section{Comentarios finales}

Una de las características centrales de la sentencia mexicana del 2008 es, sin duda, el minimalismo y la ambigüedad de sus pronunciamientos en materia de derechos. Son muchos los rasgos que convergen hacia esta conclusión. En primer lugar, la Corte se compromete tan poco como puede en la operación de calificar o precisar la modalidad constitucional de protección a la vida; el grueso de su argumentación es negativa, en el sentido de que puntualiza lo que no es sostenible: la vida no puede considerarse el derecho más importante por las razones señaladas por los actores; la vida no es un derecho absoluto; la Convención Americana no obliga a penalizar los ataques a la misma desde la concepción, etcétera. El alcance de lo que queda positivamente sentado es incierto: por un lado, el desarrollo de las páginas 153 a 158 sugiere que el derecho a la vida no está protegido en la Constitución mexicana; por otro, el análisis de las páginas 158 a 174 deja claro sí lo está en los tratados internacionales de derechos humanos firmados por México, aunque no se precisa la significación funcional de este reconocimiento (vistas las reglas que ordenan el sistema de fuentes); posteriormente, sin embargo, la resolución califica a la vida de "bien" constitucional e internacionalmente protegido, ya no de "derecho", aunque la explicación que acompaña esta

\footnotetext{
44 Ibíd., p.183.

45 Ibíd., pp. 183-184.

46 Ibíd., pp. 187-190. La Corte menciona por último las dificultades de tipo práctico a que se enfrentaría la opción de reconocer una participación decisoria a un participante masculino, en la medida en que en una etapa temprana del embarazo puede ser difícil identificar al padre potencial.

47 Ibíd., pp. 190-191.
} 
calificación, con pretensión recapitulatoria, hace equivalente la idea de "bien" a la de "derecho en un sentido relativo e interdependiente con los demás derechos" ${ }^{\prime 48}$.

De igual forma, no hay una verdadera exploración de los derechos fundamentales involucrados por el cruce de argumentos y contraargumentos que convergían en la litis: dejando aparte la cuestión de la vida, los ingredientes constitucionales de más obvia relevancia aparecen sólo de manera esquinada, cuando el fallo hace referencia a las motivaciones destacadas por la Asamblea del DF en apoyo de la reforma. Aun así, la mención a los derechos de las mujeres es rápida, genérica, y no parece existir ninguna intención de desarrollar una lectura constitucional sistemática desde esa perspectiva ${ }^{49}$; no se elabora, por ejemplo, la diferencia que en términos de derechos involucrados representa un esquema que prevé un permiso no calificado de aborto durante un determinado periodo frente a los esquemas tradicionales basados en "indicaciones"; no hay elementos que permitan determinar si la Corte se aproxima a los derechos reproductivos desde un paradigma básico de libertad, de igualdad o de dignidad ${ }^{50}$; ni siquiera menciona la sentencia un derecho que pocas constituciones contemplan con un grado comparable de especificidad: el que declara que todas las personas tienen derecho a decidir acerca del número y espaciamiento de sus hijos, presente en el artículo $4^{\circ}$ de la Constitución mexicana ${ }^{51}$.

Por fortuna, dentro de la lógica del argumento básico del fallo, estas indeterminaciones no son tan problemáticas porque deben estimarse, en realidad, irrelevantes: el argumento básico es que la constitucionalidad o inconstitucionalidad de la ley no depende de los derechos o bienes constitucionalmente protegidos que estén en juego, sino de los resultados que arroje una lectura textual de la Constitución (y de los tratados) centrada exclusivamente en la detección de obligaciones o prohibiciones al legislador de penalizar o despenalizar conductas.

Como puede observarse, el argumento decisivo es también un argumento que le permite a la Corte evitar, nuevamente, expresar o reconstruir lo que la Constitución dice. Si contraponemos, al solo efecto de dar énfasis al análisis, un modelo de interpretación constitucional integralista -i.e., que prefiere la lectura abstracta sobre la concreta, que privilegia la interpretación sistemática y que cuida la relación de la decisión con el cuerpo jurisprudencial heredado y con algún tipo de reconstrucción de los fundamentos filosóficos de la Constitución- a un modelo textualista -i.e., que privilegia lo concreto sobre lo abstracto, que tiende a minimizar el ámbito de lo que la Constitución

48 Ibíd., p. 175. En el derecho comparado, la categoría de "bien constitucionalmente protegido" se ha usado precisamente en contraposición con la categoría de "derecho fundamental". Así, en la sentencia 53/1985, el Tribunal Constitucional español declaró que en el contexto de la Constitución española el nasciturus no podía considerarse titular del derecho fundamental a la vida porque no era una persona, pero que debía ser reconocido como un "bien constitucionalmente protegido" al que la regulación debía conceder algún tipo de peso, junto a los derechos constitucionales involucrados. La sentencia colombiana de 2006 otorga también protagonismo a esta noción: según la Corte, el derecho a la vida presupone la titularidad para su ejercicio y dicha titularidad está restringida a la persona humana; la vida del embrión puede ser vista como bien constitucionalmente relevante con protección gradual, variable en las diferentes etapas (Corte Constitucional de Colombia, Sentencia C-355 de 2006, de 10 de mayo de 2006, pp. 227-234).

49 Recordemos que lo único que la Corte directamente señala, tras la extensa descripción de los "motivos" del legislador, es lo siguiente: "[e]ste Tribunal considera que la medida utilizada por el Legislador resulta de este modo idónea para salvaguardar los derechos de las mujeres, pues la no penalización de la no interrupción del embarazo tiene como contraparte la libertad de las mujeres para que decidan respecto de su cuerpo, de su salud física o mental e, incluso, respecto de su vida". Cit., p. 183.

50 Véase, por ejemplo, SIEGEL, R. Dignity and the Politics of Protection: Abortion Restrictions Under Casey/Carhart. Yale Law Journal № 177: pp. 1694-1800; (2008) para una lectura de la jurisprudencia estadounidense desde el paradigma de la dignidad y alusiones los paradigmas de la igualdad y de la libertad que han jugado un papel relevante en etapas anteriores del debate en ese país.

51 Esto marca un claro punto de continuidad con la sentencia del 2002 y con la orientación general de las demandas. La única referencia al artículo citado se hace cuando se abordan los argumentos centrados en los derechos reproductivos de los hombres, en las pp. 187-190. 
deja decidido frente a lo que está por decidir, que no somete automáticamente cualquier criterio al test de coherencia con un "sistema" (normativo, jurisprudencial, filosófico) cuya existencia no se da por descontada- claramente Aborto // debe asociarse con el segundo modelo ${ }^{52}$.

La estrategia acogida por la Corte tiene ventajas e inconvenientes claros. Su virtud es, a buen seguro, constituir un tipo de razonamiento que fue capaz de organizar la convergencia de una mayoría de Ministros en favor de la constitucionalidad de la ley: quizá si se hubiera decidido hablar fuerte y extensamente de "lo que la Constitución dice" en materia de derechos sexuales y reproductivos, o de igualdad, la disonancia del conjunto hubiera inhibido peligrosamente las posibilidades reales de adoptar una decisión ${ }^{53}$. La sentencia confiere además una gran centralidad al debate acerca de los buenos y malos usos del derecho penal en una democracia -debate sin duda entre los más relevantes cuando del aborto se trata-, da base para hacer un contraste interesante entre control de constitucionalidad de leyes restrictivas de derechos y leyes promotoras de derechos (aunque no llegue a formularlo) y juega una carta de deferencia al legislador democrático que tiene bastante sentido dentro de la lógica federal del sistema constitucional mexicano.

Los inconvenientes son también claros. En primer lugar, la estrategia textualista no es totalmente representativa de la jurisprudencia reciente de la Corte y no será fácil mantenerla en futuros casos de derechos ${ }^{54}$. En segundo lugar, la construcción de la esclusa que hace posible en este caso la separación entre el discurso de los derechos y el discurso sobre el espacio de lo constitucionalmente lícito, puede mostrar su ineficacia en casos futuros que lleguen a la Corte ya argumentados en función de sus términos exactos ( $y$, desde luego, como la propia resolución sugiere, no es aplicable cuando el derecho penal no se contrae, sino que se mantiene o avanza ${ }^{55}$. Y en tercer lugar, la resolución apenas deja elementos o herramientas para la discusión y resolución de casos futuros. Cuando Ilegue a la Corte un caso de aborto de otro Estado, o el tema de la eutanasia (recientemente abordado también por el legislador del DF), o el de la anticoncepción de emergencia, todo deberá ser rediscutido de nuevo. La extensión de lo decidido, como en Aborto I, es muy limitada, y, según dispone una nota final de la sentencia, las consideraciones más importantes no son obligatorias (en los términos que le corresponderían a un pronunciamiento apoyado por

52 En este punto deseo contraponer de un modo muy general dos aproximaciones a la interpretación de la Constitución y del derecho en general que han sido usadas y teorizadas bajo nombres y con detalles cambiantes (teorías "subjetivistas", "intencionalistas", "originalistas" versus teorías "objetivistas" "constructivistas", "morales", etcétera) y no siempre en planos de análisis iguales, ni mutuamente excluyentes, pero en sus grandes rasgos reconocibles en el debate jurídico de todas las democracias constitucionales de hoy. Véase, por ejemplo, BARBER, S. y FLEMING, J. Constitutional Interpretation. The Basic Questions (Nueva York. Oxford University Press, 2007), para un mapeo útil de las principales corrientes involucradas en el mismo, bajo las denominaciones al uso en Estados Unidos.

53 En cualquier caso, para analizar exhaustivamente este extremo hay que esperar a contar con las opiniones separadas que acompañarán la resolución.

54 Aunque tradicionalmente la Corte mexicana ha operado como un exponente bastante puro de lo que es la tradición "formalista" latinoamericana (véase, para una reconstrucción general breve y útil del formalismo jurídico, ATIENZA, M. El sentido del derecho. $2^{a}$ edición. Barcelona. Ariel, 2003, pp. 276-279) en los últimos años encontramos un buen número de instancias de reconocimiento de derechos fundamentales no expresados (véase, por ejemplo, el Amparo en revisión 1780/06, donde se reconoce el derecho fundamental al mínimo vital) y un fuerte aumento de argumentaciones principialistas y de los razonamientos sistemáticos sobre la base de un texto fundamentalmente identificable con el modelo de "constitución de detalle".

55 Hay motivos para pensar que el razonamiento de la resolución es escaso incluso en términos del estándar que ella misma establece, al apuntar que la "descriminalización" no puede ser en cualquier caso discriminatoria (las demandas contenían un cargo claro en tal sentido: consideraban que las normas establecían diferencias discriminatorias entre los embriones mayores y menores de 12 semanas). Igualmente puede pensarse que, una vez aceptada la existencia de un bien constitucionalmente protegido, era necesario someter la medida despenalizadora a un examen de proporcionalidad. 
ocho votos) por no haber sido coincidentes las razones para el reconocimiento de la validez de las normas ${ }^{56}$.

Si Aborto I, nacido de una votación dividida, fue perdiendo fuerza y relevancia al ir desapareciendo los referentes constitucionales que le daban sustento, podemos decir que Aborto II, a pesar de la votación, nace sin fuerza. Por los términos en que está redactada, por la ausencia de pronunciamientos de contenido constitucional que se proyecten sobre todos los subordenamientos del sistema (y no solamente sobre el del DF), por lo tenue de las referencias a resoluciones de otras cortes, por la debilidad de su fuerza vinculante, la sentencia no busca un "diálogo" articulado en términos constitucionales fuertes. Para lo bueno y para lo malo, la sentencia expulsa -al menos temporalmente- el debate sobre el aborto del mundo de la constitucionalidad y de las cortes y lo traslada al mundo de la política y de las legislaturas (quienes, por cierto, parecen decididas a no desaprovechar la oportunidad) ${ }^{57}$.

En cualquier caso y para cerrar destacando un punto que me parece interesante en el ámbito de un debate regional interesado por decantar buenas opciones para lograr o reforzar la garantía de los derechos sexuales y reproductivos, creo que la discusión mexicana sobre la normativa del DF muestra la enorme importancia estratégica del tipo de "saque" legislativo al que luego están destinadas a enfrentarse las Cortes: el caso parece mostrar que la opción de cambiar la técnica de regulación tradicional y retirar el derecho penal por la vía de redefinir los confines del delito, en lugar de simplemente aumentar el número o el alcance de las excepciones que operan sobre un trasfondo general de penalización, puede influir de manera importante en el desenlace del debate. Para una Corte constitucional, sin duda, la perspectiva de emitir una resolución que supone volver a penalizar lo despenalizado es, tanto en términos de carga argumental como en términos de costo institucional, mucho más difícil que la opuesta; además, como evidenciaba el primer proyecto de resolución discutido por los Ministros, en este tipo de escenario muchos de los argumentos esgrimidos contra la ley conducen lógicamente a la invalidación y "desaparición" de las normas tipificadoras del delito, un resultado que puede acabar en pesadilla para quienes la han impugnado, no siempre susceptible de ser bloqueada mediante sentencias interpretativas o manipulativas de los preceptos legales analizados ${ }^{58}$.

56 Cit., p. 208. Habrá que debatir con calma, en cualquier caso, qué virtualidad real tiene una acotación como ésta por parte de la Corte en el marco fijado por su normativa reguladora, según la cual lo apoyado por una mayoría de al menos ocho votos constituye jurisprudencia.

57 Desde agosto de 2008 seis Estados han discutido (y uno -Baja California- ha aprobado) reformas constitucionales orientadas a plasmar la protección de la vida humana desde la concepción. También existe una iniciativa de reforma a la Constitución Federal en el mismo sentido.

58 Es el caso, por ejemplo, de los argumentos que denuncian defectos de las normas impugnadas desde la perspectiva de la taxatividad. 